\title{
A mulher no contexto da agricultura familiar no sertão do Rio Grande do Norte
}

\author{
Women in the context of family farming in the interior of Rio Grande do Norte \\ Mujeres en el contexto de la agricultura familiar en el interior de Rio Grande do Norte
}

Recebido: 04/08/2021 | Revisado: 11/08/2021 | Aceito: 15/08/2021 | Publicado: 17/08/2021

\author{
Raimunda Adlany Dias da Silva \\ ORCID: https://orcid.org/0000-0002-3600-6186 \\ Universidade Federal da Paraíba, Brasil \\ E-mail: adlanydias@gmail.com \\ Francisca de Souza Miller \\ ORCID: https://orcid.org/0000-0003-1739-5152 \\ Universidade Federal do Rio Grande do Norte, Brasil \\ E-mail: fransmiller56@yahoo.com.br \\ Juliana Espada Lichston \\ ORCID: https://orcid.org/0000-0002-4042-4524 \\ Universidade Federal do Rio Grande do Norte, Brasil \\ E-mail: j.lichston@gmail.com
}

\begin{abstract}
Resumo
A mulher agricultora participa das esferas social, econômica e política no contexto agrícola familiar, transcendendo ao cuidado com o lar e contribuindo no sustento familiar. Por meio de pesquisa empírica com aplicação de questionário semiestruturado, o presente estudo objetivou compreender a dinâmica e a participação de mulheres agricultoras cooperadas da Cooperativa Potiguar de Apicultores e Desenvolvimento Rural Sustentável - COOPAPI na localidade do Sítio Córrego, Município de Apodi, Estado do Rio Grande do Norte, no contexto da agricultura familiar, e verificar a aceitação do grupo ao cultivo de oleaginosas, crescente na região. As agricultoras trabalham ativa e efetivamente na criação de animais de pequeno porte, cuidado de plantas, comercialização de frutas e produção de bolos. Além do cuidado com o lar, desenvolvem atividades múltiplas para garantir a complementação do sustento familiar, seja no setor doméstico, agrícola ou comercial. Tais tarefas são, muitas vezes, não remuneradas, vistas ainda apenas como "ajuda", o que contribui para invisibilidade e desvalorização do trabalho agrícola feminino.
\end{abstract}

Palavras-chave: Campesinato; Trabalho agrícola; Mulher no campo.

\begin{abstract}
The woman farmer participates in the social, economic and political spheres in the family agricultural context, going beyond the care of the home and contributing to the family's livelihood. Through empirical research using a semistructured questionnaire, this study aimed to understand the dynamics and participation of cooperative women farmers of the Potiguar Beekeepers Cooperative and Sustainable Rural Development - COOPAPI in the locality of Sítio Córrego, Municipality of Apodi, State of Rio Grande North, in the context of family farming, and to verify the group's acceptance of oilseed cultivation, which is growing in the region. Farmers work actively and effectively in the creation of small animals, plant care, fruit marketing and cake production. In addition to caring for the home, they carry out multiple activities to ensure the complement of family livelihood, whether in the domestic, agricultural or commercial sectors. Such tasks are often unpaid, still seen only as "help", which contributes to the invisibility and devaluation of female agricultural work.
\end{abstract}

Keywords: Peasantry; Farm work; Woman on the field.

\section{Resumen}

La agricultora participa en los ámbitos social, económico y político del contexto de la agricultura familiar, yendo más allá del cuidado del hogar y contribuyendo al sustento de la familia. A través de una investigación empírica mediante un cuestionario semiestructurado, este estudio tuvo como objetivo comprender la dinámica y participación de las cooperativas de mujeres agricultoras de la Cooperativa de Apicultores Potiguar y Desarrollo Rural Sustentable COOPAPI en la localidad de Sítio Córrego, Municipio de Apodi, Estado de Río Grande. Norte, en agricultura familiar, y verificando la aceptación del grupo del cultivo de oleaginosas, que viene creciendo en la región. Los agricultores trabajan activa y eficazmente en la cría de pequeños animales, el cuidado de las plantas, la comercialización de frutas y la producción de pasteles. Además de cuidar el hogar, realizan múltiples actividades para asegurar el complemento del sustento familiar, ya sea en el sector doméstico, agrícola o comercial. A menudo, estas tareas no son remuneradas, todavía se consideran sólo como "ayuda", lo que contribuye a la invisibilidad y devaluación del trabajo agrícola feminino.

Palabras clave: Campesino; Trabajo agrícola; Mujeres en el campo. 


\section{Introdução}

Mesmo com várias conquistas adquiridas pelas mulheres, como a participação em diversas esferas, econômica, social e política, por exemplo, elas ainda sofrem com a sobrecarga de atividades e horas de trabalho (Arzabe; Martins, 2018). Essa desvalorização também ocorre no contexto produtivo agrícola.

Desde o período colonial, observou-se a acumulação de atividades pelas mulheres, nestas incluíam o cuidado com o lar e sustento da família. No período de guerras, as mulheres eram as principais no suprimento de mão de obra no mercado, visto a ausência dos companheiros em casa (Macedo et al., 2018).

Macedo et al. (2018, p.13) relatam que as contribuições da mulher, para o sustento da família, ultrapassam "o simples" cuidado com o lar, passando a ser a principal e/ou única provedora do lar. Ainda conforme os autores, essa participação tão representativa e essencial à sobrevivência da família sempre foi negligenciada e pouco valorizada, pois recebiam como pagamento valores inferiores aos homens, mesmo realizando tarefas similares.

Segundo Heredia (2013) a desvalorização do trabalho rural feminino é reforçada, quando este é visto apenas como “ajuda" pelo cônjuge, uma vez que, as atividades relacionadas à roça são de responsabilidade do homem. No entanto, estas atividades não eram exclusividade masculina, uma vez que as mulheres sempre participavam e contribuíam de forma ativa.

Alves, Sell e Castro (2018) apontam ainda, que a desvalorização do trabalho agrícola feminino é um problema persistente, que afeta a visibilidade da mulher e mascara o seu potencial para a contribuição na produção agrícola. Já em relação ao trabalho realizado pelos homens, seja no passado ou na atualidade, observa-se que a força masculina e a participação no meio produtivo são ações postas em destaque (Neves; Medeiros, 2013, p. 10).

Os camponeses brasileiros do período colonial detinham alguns "privilégios", dentre os quais pode-se pontuar: a casa, para moradia; a renda semanal; o roçado, local onde poderiam cultivar; e o criatório destinado à criação de animais de pequeno porte (Scott, 2009, p.250-251). Mesmo com essas aparentes "vantagens", as famílias conviviam em constante risco de perda do investimento, seja de força física ou financeira.

Nos engenhos é facilitada a criação de aves e bichos de pequeno porte, o que melhora a dieta e facilita o transporte. Mas nos engenhos particulares há muita repressão contra os animais de pequeno porte por duas razões. Primeiro, nos arruados, as senzalas antigas, a proximidade das casas e o movimento da vizinhança dificultam a criação dos bichos. Segundo a própria administração do engenho se encarrega de matar porcos e cabras que se aventuram nos canaviais do proprietário. O risco do investimento familiar é evidente. (Scott, 2009, p. 251).

Nas atividades agrícolas familiares, o roçado é definido como conjunto de cultivos com finalidade de subsistência da família, porém, destacam-se algumas das culturas tidas como principais (Heredia, 1979b).

Conforme Medeiros e Ribeiro (2011), no segmento agrícola:

A participação do trabalho feminino na agricultura familiar sempre foi subestimada. Pelo fato de as mulheres serem, na naturalização das atribuições de gênero, as responsáveis pela reprodução social do grupo, as atividades produtivas desenvolvidas por elas são consideradas como parte das tarefas atribuídas ao papel de mãe e esposa, consideradas "ajuda" e "complementares" àquelas desenvolvidas pelos homens. (Medeiros; Ribeiro, 2003 p.02).

Paulilo (2000) observa que entre atividades domésticas, trabalhos rurais e comerciárias, 46\% da mão de obra é feminina, uma contribuição muito expressiva.

Uma diferença fundamental entre os sexos é que, para a maioria das mulheres, família e trabalho andam juntos e, para a maioria dos homens, trabalho significa emprego assalariado que exige tempo fora de casa. As atividades de trabalho das mulheres não são bem captadas pelas estatísticas oficiais, principalmente quando trabalham na agricultura. (Paulilo, 2000, p. 238). 
Nos últimos 20 anos, observou-se a ampliação de movimentos e estratégias governamentais e não governamentais em busca de inserção, valorização e visibilidade das mulheres no setor agrícola. A ampliação de financiamentos, assistência técnica, programas de comercialização da produção, movimentos sociais, conferências e selos sociais exclusivos às mulheres agricultoras são algumas das estratégias desenvolvidas.

Em 2015, um marco de extrema relevância para as mulheres agricultoras foi o início da campanha \#Mulheres Rurais, que tem como principal objetivo a valorização do trabalho da mulher no meio rural (Mapa, 2019a). O lema da campanha foi: "Sou trabalhadora rural, não sou ajudante".

Já em 2018, outro importante marco foi a criação do selo "Aqui Tem Mulher Rural". Criado com o intuito de identificação da produção realizada por mulheres, tornando visível seu papel estratégico na batalha pela soberania alimentar e como protagonistas do desenvolvimento sustentável (Mapa, 2018). O selo contribui ainda para garantia da autonomia feminina.

Outro período representativo, não só para agricultoras, mas para todo setor agrícola, foram os dias 27,28 e 29 de maio de 2019, quando ocorreu a Conferência de Roma. Neste evento, foi implantado o plano que prevê a erradicação da fome em um período de 10 anos - início em 2019 e finalização em 2028 - e cujos objetivos específicos são: criar um ambiente político propício para fortalecer a agricultura familiar; apoiar jovens; fomentar a igualdade de gênero e o papel das mulheres rurais (Mapa, 2019b).

A maioria das mulheres envolvidas com a agricultura $(50,3 \%)$ se enquadra no perfil economicamente ativo (Pnad, 2015). Em dados preliminares no censo agropecuário de 2017, para o pessoal ocupado com atividades agropecuárias, a quantidade de mulheres que ocupa o setor agropecuário com laço de parentesco foi de 3.770 .496 indivíduos, no Brasil. Já para o Rio Grande do Norte o número foi de 37.798 (Ibge, 2017) mulheres.

Em relação ao setor cafeeiro do Nordeste brasileiro, Meira et al. (2013) ressaltam que a participação das mulheres está em progressiva ascensão, em especial no Município da Barra do Choça, na Bahia, onde as agricultoras se mostram bastante satisfeitas, em especial, porque é viável conciliar trabalho e família. Maia e Siqueira (2011) observaram a importância do protagonismo feminino na agricultura e o convívio em sistema de associação, pois essa relação possibilitou às mulheres uma melhor compreensão do seu papel e contribuição para melhoria do meio em que vivem, proporcionando uma sensação de liberdade.

Outra dificuldade encontrada por agricultores familiares situados na Região Nordeste são as condições edafoclimáticas, como a irregularidade pluviométrica e os solos salinos, características de clima semiárido predominante na região. Além disso, as secas prolongadas afetam diretamente os agricultores, causando perdas drásticas na produção de insumos e comprometendo a sobrevivência da família. Apesar dessas dificuldades, as regiões interioranas do Estado do Rio Grande do Norte são responsáveis por grande parte da produção de alimentos que abastecem a população urbana do Estado, com expressivo trabalho feminino (Azevedo; Nunes, 2013).

O presente estudo busca: compreender a dinâmica e a participação de mulheres agricultoras da Cooperativa Potiguar de Apicultores e Desenvolvimento Rural Sustentável - COOPAPI, da localidade Sítio Córrego, município de Apodi, Rio Grande do Norte, no contexto da agricultura familiar e verificar a aceitação do grupo à cultura de oleaginosas e com potencial para a região. 


\section{Metodologia}

\subsection{Público alvo e área de estudo}

A Cooperativa Potiguar de Apicultores e Desenvolvimento Rural Sustentável - COOPAPI foi fundada em abril de 2014, envolve 399 agricultores/as familiares de todos os municípios do Rio Grande do Norte, sendo que destes 279 são cooperados e 120 agricultores/as são fornecedores de algodão agroecológico. A instituição estabelece parceria com 16 casas de mel, 22 associações e possui central de cooperativa situado no centro de Apodi-RN. Do total de filiados a cooperativa 17 são mulheres, com cadastro no seu nome, prática recente da cooperativa, visando dar visibilidade às mulheres, pois inicialmente os cadastros eram feitos somente no nome do chefe da família e abrangia a família toda.

Foram entrevistadas 15 mulheres agricultoras filiadas à Cooperativa Potiguar de Apicultores e Desenvolvimento Rural Sustentável - COOPAPI, o que corresponde a 88,23\% do total de filiadas. As entrevistadas são moradoras da localidade Sítio Córrego, região rural do Município de Apodi, no sertão do Rio Grande do Norte. O Sítio foi assim nomeado pelos primeiros moradores da região devido à presença de um córrego que cruzava as terras.

Na região tem sido ampliada práticas de pesquisas com Carthamus tinctorius, com foco na produção de matrizes vegetais energéticas, dando visibilidade ao potencial da região para o setor de combustíveis renováveis. O destaque para o potencial regional no setor é visível com a existência do curso de nível médio técnico, na área de combustíveis ambientalmente compatíveis, no Instituto Federal do Rio Grande do Norte, campus Apodi, além de resultados animadores de cultivos experimentais nas dependências da instituição.

\subsection{Procedimentos metodológicos}

A pesquisa empírica foi de caráter qualitativo e quantitativo e fez uso de questionário semiestruturado seguindo o sugerido por Mekesenas (2002), organizado em duas partes. A primeira refere-se à caracterização das famílias, mediante o levantamento das seguintes informações: faixa etária; estado civil; quantidade de membros da família e grau de escolaridade, com finalidade de conhecer previamente o grupo. A segunda foi estruturada em 15 questões de caráter discursivo e objetivo abordando os seguintes temas: atividades desenvolvidas no dia a dia; atuação na agricultura e em atividades de negociação direta; conhecimento do Carthamus tinctorius e programas de incentivo ao cultivo de oleaginosas; conhecimento de técnicas de cultivos de oleaginosas; a aceitação ao cultivo de uma nova cultura e quais as implicações para este cultivo.

O questionário foi previamente submetido e aprovado pelo comitê de ética da Universidade Federal do Rio Grande do Norte sub o número 01422918.6.0000.5537. Foram realizadas visitas prévias à região e à cooperativa, divulgando pesquisas científicas com o cultivo em campo de Carthamus tinctorius no município de Apodi em um período de 3 anos. As visitas à cooperativa objetivaram conhecer a gestão, as parcerias e das atividades nela desenvolvidas. O contato com a comunidade de mulheres da atual pesquisa foi feito ao longo de três anos, de 2017 a 2019. Inicialmente essas mulheres foram mapeadas, dentre os agricultores da cooperativa, depois fizemos entrevistas e intervenções com palestras sobre oleaginosas e distribuição de material didático. Foram vários encontros durante esse período mencionado. Durante essas visitas houve a aplicação do questionário, sendo encerrado em fevereiro de 2019. As contribuições das mulheres participantes foram tabuladas e analisadas a partir do conteúdo contido nas respostas por similaridade destes e aferida a porcentagem. Em seguida, foi estabelecido um diálogo com a literatura para compreender a dinâmica das atividades, anseios e desejos das agricultoras.

\section{Resultados e Discussão}

A COOPAPI fornece uma variedade de produtos alimentícios e não alimentícios para o semiárido nordestino, como geleias, polpas e doces, produz ainda artesanato a partir do algodão agroecológico. 
O grupo amostral da presente pesquisa compreende mulheres agricultoras da COOPAPI, que em termos percentuais, é composto em sua maioria por mulheres com idade entre 22 e 59 anos, com uma expressão de 93,33\%. Foram observados somente $6,6 \%$ de mulheres com mais de 62 anos de idade.

No quesito estado civil, observou-se que $86,6 \%$ das mulheres entrevistadas eram casadas ou com união estável firmada e 6,6\% eram separadas, sendo o mesmo percentual observado para mulheres solteiras.

A quantidade de filhos varia entre 0 a 4 por família. Aproximadamente 33,3\% das participantes tem 1 filho e $66,6 \%$ tem entre 2 e 4 filhos.

A respeito do estado civil casada, (2017, p.12) observou, por meio de depoimento de mulheres agricultoras, no contexto agrícola familiar, que há uma relação de manutenção das tradições do grupo. A autora percebeu que todas as mulheres que participaram da pesquisa eram casadas e todas possuíam filhos. Como já citado, a dinâmica do grupo consultado no presente estudo se distingue do observado por Varotto, inclusive para a quantidade de filhos.

Para o grau de escolaridade, foi possível observar que $47 \%$ do grupo de mulheres participantes da pesquisa possuíam o ensino fundamental incompleto. Apenas 7\% ensino superior completo, mesmo percentual para o nível de ensino superior incompleto (Figura 1). Quando somamos a quantidade de participantes com ensino fundamental incompleto, completo e médio incompleto obteve-se um total de $73 \%$, dados que demonstram a problemática do acesso à educação no contexto agrícola familiar. A baixa escolaridade entre as mulheres no campo também foi vista por Quaresma (2015). Vespucci et al. (2019) destaca que a qualificação dos agricultores e agricultoras proporciona o desenvolvimento e prosperidade das suas propriedades. Alguns fatores estão atrelados a isso, dentre eles estão: primeiro, relaciona-se com o início do trabalho ainda na infância e o segundo a precariedade de acesso às políticas públicas no setor educacional (Mahl, Stein e Costa, 2017).

Figura 1: Grau de escolaridade das mulheres agricultoras do Sítio Córrego Município de Apodi-RN. F.I: fundamental incompleto; F.C: fundamental completo; M.I: médio incompleto; M.C: médio completo; S.I: superior incompleto; S.C: superior completo.

\section{Escolaridade F.I Escolaridade M.C}

\section{Escolaridade F.C}

Escolaridade S.C

\section{- Escolaridade M.I}

Escolaridade S.I

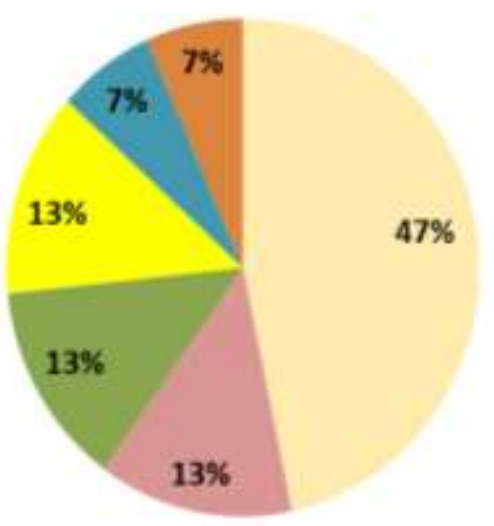

Fonte: Pesquisa de campo (2019).

Como mencionado acima, as mulheres avaliadas são residentes da localidade Sítio Córrego, sendo a categoria sítio definida por Heredia (2013, p.8) de duas maneiras: uma em oposição a grandes produções como fazendas, e outra como forma de delimitação territorial, incluindo o local em que os agricultores familiares cultivam suas culturas e a casa onde moram. 
Nesse local, elas desenvolvem diversas atividades, dentre as quais pode ser destacado o cuidado com a casa, perceptível em algumas expressões utilizadas pelas participantes, como: Agricultora 1 "Cuido da casa...”; Agricultora 1“Arrumo a casa...”, sendo atividade comum às mulheres, citada por $60 \%$ das participantes.

O trabalho de cuidado com a casa é cotidiano, repetitivo e, acima de tudo, não remunerado (Bradão; Santos, 2016), tendo pouca visibilidade, camuflando assim, a representatividade, a dedicação, o esforço e a árdua jornada dedicada pelas mulheres ao lar (Woortmann, 2009).

A casa é o espaço destinado à moradia da família e a porção de terra ao seu entorno é considerado "terreiro". Os cuidados com o terreiro também são designados às mulheres, responsáveis por mantê-lo limpo e está intimamente ligado à casa, o que é perceptível na fala de uma interlocutora quanto às suas atividades: Agricultora 3 "Cuidar da casa, ciscar o terreiro, apanhar frutas...".

Heredia (2013, p.9-10) aponta o terreiro como local de socialização entre membros da família e amigos, seja para falar de assuntos relacionados à plantação ou para diminuição da sensação térmica (calor). Com isso, a manutenção dessa área constantemente limpa e em condições de uso é importante no convívio social da família. Diferente do observado por Heredia (2013) para o quesito árvores frutíferas e local de plantio, observamos na localidade de Sítio Córrego que as árvores frutíferas não se concentram no terreiro da frente da casa, mas sim, nas laterais e nos fundos da residência como os quintais das pescadoras de Patané e Camocim no município de Ares-RN, observado por Miller (2012). De acordo com Heredia as árvores frutíferas que ficavam na frente das casas não eram iguais às que ficavam no terreiro dos fundos, local onde era possível ver a criação de animais de pequeno porte.

O terreiro dos fundos da casa está destinado fundamentalmente às aves domésticas e ao chiqueiro dos porcos; é também ali que as cabras passam a maior parte do dia. Em alguns setores de espaço as mulheres lavam a louça e fazem a higiene das crianças. Muitas vezes encontram-se neste local algumas árvores frutíferas, mas de tipo diferente da plantadas na frente da casa. Nos fundos, frequentemente, estão os mamoeiros e bananeiras, enquanto na frente são plantadas mangueiras e jaqueiras. (Heredia, 2013, p. 10).

$\mathrm{Na}$ fruticultura realizada por agricultoras da localidade Sítio Córrego, as principais culturas citadas foram: manga, seriguela, acerola, goiaba e caju. Estas são comercializadas com a COOPAPI, atividade complementar de renda voltada ao sustento da família. A cajucultura é a principal fonte de renda da região. Por consequência da estiagem prolongada, ocorrida nos últimos anos, a produção foi afetada, levando assim, ao investimento em outras culturas frutíferas para comercialização como acerola e goiaba, também utilizadas para o consumo da família.

Observou-se ainda a diversificação de atividades, como combinação de práticas de fruticultura, atividades domésticas, comercialização de frutas e produtos oriundos de técnicas manuais (artesanato), além da criação de aves, como se pode observar nas seguintes falas: Agricultora 5 "As atividades de casa, trancinha, limpar o terreiro, pegar os ovos, cuidar dos pés de manga, seriguela". Outra: Agricultora 8 "Trabalho na agricultura, no sábado na feira, na agricultura familiar, na produção de vassoura, chapéu e esteira de palha (artesanato)". E uma terceira: Agricultora 9 "Cuido da casa, do filho, faço artesanato, cuido da planta, as frutas vão para a cooperativa".

Outra prática presente no grupo é a horticultura, como citado por uma participante desta pesquisa: "Atividades de casa e cuidar da horta." prática realizada comumente por mulheres. A produção oriunda da horta é usada para o consumo da família, o excedente é comercializado para compra de materiais e insumos que não produzem em suas pequenas propriedades.

Os cuidados com a Horta eram direcionados às mulheres, devido essa ser próxima das residências, mas tem sido observado mulheres desenvolvendo práticas agroecológicas, que também são desenvolvidas na agricultura familiar, cultivo de hortaliças entre outros em regiões do semiárido (Varotto, 2017, p.6). 
Além do cultivo de árvores frutíferas, do cuidado com culturas de subsistência e da horta, as práticas de artesanato também estão presentes no Sítio Córrego, traduzidas no relato das mulheres agricultoras.

Cunha (2002) cita que a combinação da agricultura e do extrativismo vegetal de cunho familiar com o artesanato esteve presente também em várias sociedades pesqueiras, nas quais a pesca era a principal fonte de proteína. Além disso, a palmeira era a fonte vegetal para a retirada da matéria-prima necessária à produção de colheres e esculturas. As palmeiras também são usadas por mulheres agricultoras da localidade Sítio Córrego na produção de chapéu, esteiras e vassouras, por técnica passada de geração para geração. Os produtos oriundos destas atividades são comercializados na localidade Sítio, entre os moradores e na feira, que ocorre aos sábados na zona urbana do Município de Apodi-RN.

Zanchi e De-Souza (2019) destacam que a combinação entre produção de alimentos e artesanato, também desenvolvido por mulheres, contribui de forma expressiva na renda familiar. Apontam ainda que essas atividades são subestimadas e muitas vezes ignoradas, corroborando, então, para a não visibilidade, ausência de autonomia e influenciando, de forma negativa, na autoestima das agricultoras. Um dos principais pontos essenciais para o reconhecimento das mulheres agricultoras como produtoras do meio rural, foi o acesso aos direitos previdenciário (Paulilo, 2017 p. 403).

Segundo Sachs (2008), a agricultura familiar participa dos quatro meios de produção: a economia solidária, a economia capitalista de mercado, a pequena produção pré e protocapitalista e a produção fora do mercado, ou seja, a produção para subsistência. Woortmann (2009, p.128) chama atenção para a valorização e a importância do universo feminino no contexto dessa sociedade: "É preciso também não ignorar as relações de gênero. O universo camponês feminino é tão importante quanto o masculino".

As principais culturas agrícolas cultivadas pelas mulheres entrevistadas são o feijão, o milho e o sorgo, classificadas como de subsistência, uma vez que é de consumo direto da família ou para a aquisição de dinheiro para provisão de outros insumos e objetos necessários (Heredia, 2013, p.8). Segundo Aquino, Freire e Carvalho (2018) a agricultura familiar, no período entre 1996 e 2016, contribuiu com mais de um terço da produção agropecuária do Estado do Rio Grande do Norte, mesmo os agricultores tendo uma menor ocupação de terras, comparado a outros Estados do Brasil. Os autores apontam que há um melhor aproveitamento produtivo, mesmo com uma heterogeneidade socioeconômica, reflexo da diversificação dos padrões produtivos. Essa diversificação também pode ser observada no município de Encruzilhada do Sul, no Rio Grande do Sul, onde as mulheres desenvolviam atividades agropecuárias, com destaque para a bovinocultura mesclada com a criação de ovelhas, aves, porcos, cultivo de milho, mandioca e feijão (Lopes e Langbecker, 2018).

Nesse contexto produtivo, é sabido que o semiárido brasileiro dominante na região Nordeste possui diversas limitações, dentre elas, a mais prejudicial é a baixa precipitação pluviométrica e solos salinos. Ferreira (2011) explicita que a produção com viés agroecológico pode contornar essas limitações, aponta ainda que técnicas para estocagem de água são essenciais nesse processo. No mesmo contexto, Brasileiro (2009) verificou, na experiência de sistemas agroecológicos de agricultura familiar, que a participação feminina se mostra como diferencial, em virtude de sua maior sensibilidade aos problemas ambientais, culturais e sociais presentes na região em que estão inseridas.

Seguindo na mesma linha de pensamento, Nascimento, Rocha e Mendonça (2018) ressaltam que o conhecimento ecológico das mulheres no contexto camponês, construído em suas práticas no campo, foi lapidado, aprimorado e refinado, possibilitando a aproximação com o mundo natural.

As mulheres participam de diversas atividades, que vão além do cuidado com a casa, pois estendem-se aos animais e vegetais: Agricultora 13 "Cajucultura, fruticultura, feijão, milho, sorgo. Bovino, aves, suínos, na casa". Há ainda as atividades cumulativas, nas quais as mulheres simultaneamente cuidam da casa, dos quintais produtivos e de outras culturas produzidas nas pequenas propriedades. A forma que as mulheres experienciam a vida não é a mesma que os homens, há uma divisão na atuação contexto político-social (Saffioti, 1991, p. 153). Mesmo com os avanços em pesquisas sociais que buscam a 
visibilização das mulheres, há uma clara diferenciação na divisão e valorização do trabalho entre homem e mulheres, imputando a elas as atividades relacionadas ao lar, como apontado por Santos et al. (2020).

A diversificação de atividades, com finalidade de melhor aproveitamento das áreas destinadas à produção, são características de sistemas agrícolas familiares. Rebouças e De-Lima (2013) também acrescentam a multiplicidade de tarefas como uma estratégia que visa à aquisição de dinheiro, para garantir a alimentação e as necessidades básicas das famílias. A diversificação de produtos e a maneira como produzi-los proporciona autonomia ao agricultor familiar (Strate e Conterato, 2019).

Foi observado que $86,66 \%$ das mulheres que participaram desse estudo contribuem efetivamente para com a renda doméstica. Elas atuam em diversas atividades, seja na produção ou comercialização de produtos: Agricultora 1 "Designer de sobrancelhas..."; Agricultora 3 "Com frutas e as polpas"; Agricultora 6 "Sou aposentada, faço vassoura, artesanato, chapéu"; Agricultora 8 "Trabalho na agricultura e na feira"; Agricultora 9 "Trabalho em casa de família"; Agricultora 10 "Vendo crochê, agricultura no quintal e com caju"; Agricultora 11 "Vendo acerola, goiaba, feijão, ovo, cheiro verde e galinha"; Agricultora 13 "Vendo leite, ovos, frutas etc."; Agricultora 14 "Trabalho com o caju e nos bolos". A Figura 2 apresenta as principais ocupações classificadas como fonte complementar de renda do grupo de mulheres e retrata a agricultura como a principal fonte de renda para a família em $40 \%$, seguida de outas atividades em $27 \%$.

Figura 2: Atividades de maior contribuição para a complementação da renda familiar no Sítio Córrego, Município de ApodiRN.

\section{Agricultura $\square$ Outras $\square$ Não sei responder $\square$ bolo $\square$ Artesanato}

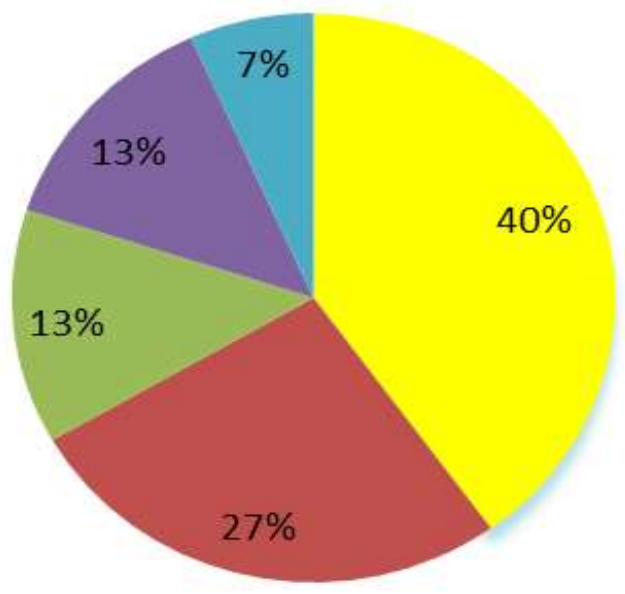

Fonte: Pesquisa de campo (2019).

As expressões "Trabalho..." e "Ajudo..." estavam presentes nas falas das mulheres e retratam como elas percebem a representatividade de suas atividades, no contexto da agricultura familiar. Heredia (2013) faz uma distinção relacionando o ambiente e as atividades desenvolvidas pelos homens e pelas mulheres. O termo trabalho é evidenciado como relacionado à roça prioritariamente de responsabilidade do homem.

Desta forma, o lugar do homem é no roçado, enquanto o da mulher, mãe de família, é na casa. As atividades no roçado, na medida em que possibilitam a produção de bens essenciais para o consumo familiar, são consideradas trabalho, em oposição às ligadas à casa, não reconhecidas como tal (Heredia, 2013, p. 49). 
É evidenciado o reconhecimento da representatividade dessas atividades, de tal modo que são designadas como trabalho; já as atividades da casa não são vistas assim. As mulheres não têm a visibilidade, elas permanecem à margem e não alcançam a centralidade do processo e visibilização como discutido por Saffioti (1991). Isso pode implicar na não valorização de atividades vinculadas ao lar, mesmo estando diretamente relacionadas àquelas que gerem renda para a família. A venda de ovos, o cultivo de vegetais, a coleta e a preparação para a venda e a própria venda de produtos cultivados nas pequenas propriedades são alguns exemplos de contribuição direta para a aquisição de recursos financeiros. Como "Considera-se assim que a mulher não trabalha e este princípio é mantido mesmo quando ela, em certas ocasiões, realiza tarefas no roçado" (Heredia, 2013, p.50).

A valorização do trabalho feminino, independentemente da esfera, deve ser exercitada, uma vez que contribui para o bem-estar e a autoestima das mulheres: Agricultora 8 "Faço artesanato desde pequena, mas não gosto muito, porque ninguém dá valor, costurava antes e agora não me interesso muito". Como expressado por uma agricultora, a valorização do que é produzido por suas mãos tem "poder" de impulsionar a produção e dedicação. Por outro lado, a desvalorização causa a rejeição das atividades, mesmo estas sendo bem conhecidas e dominadas. Silva (2019) afirma que é através do autorreconhecimento e da participação que mulheres romperão a desvalorização do seu trabalho e, assim, transitarão da visão de ajuda para a constatação de trabalho, com toda representatividade intrínseca ao termo. Chayanov (1974) em seu estudo intitulado $L a$ organización de la unidad económica campesina, relata:

"Em geral a mulher trabalha mais do que o homem, mas seu trabalho não é tão duro. Os adolescentes trabalham menos dias que os adultos. A distribuição de seu trabalho nos setores da fazenda é de acordo com o sexo; em geral os jovens se ocupam mais da agricultura e as jovens dedicam muitos dias ao trabalho doméstico" (Chayanov, 1974, p. 210).

Para as atividades que propiciam satisfação, o motivo pelo qual esta satisfação se manifesta é perceptível nas falas das interlocutoras: Agricultora 2 "Ser diretora da cooperativa, porque gosto de ter mais contato com as outras pessoas". Outra destaca ainda que: Agricultora 8 "Ir para a feira, porque troco ideias, não é tanto pelo dinheiro e porque agente (sic) tem mais conhecimento". Ambas destacam linhas de pensamentos similares, nas quais o dinheiro não é o principal motivo de satisfação, mas sim a relação com as outras pessoas, o compartilhar de informações, conhecimento o contato com novas experiências.

A inserção das mulheres no mercado e a valorização das atividades desenvolvidas por elas têm propiciado mudanças em relação à visão do seu papel social. A pluralidade de atividades ganha importância no meio agrícola porque propicia maior autonomia e maior socialização dentre o grupo social quando estas têm oportunidade de transitar entre propriedades (Silva e Schneider, 2010). A socialização é um ponto de destaque de outra colaboradora da atual pesquisa: Agricultora 14 "Fazer bolo, porque estamos juntos é bom, passa o tempo".

Algumas participantes da pesquisa destacaram que a segurança financeira era desejável: Agricultora 15 "Gostaria de ter um trabalho fixo". Outra Agricultora 14: "Queria uma atividade que recebesse dinheiro todos os meses". Essas falas que corroboram o que foi observado por Alves, Sell e Castro (2018). Segundo eles, é possível perceber que a ausência de trabalho com renda fixa atrelado ao fator educação precária, influencia diretamente e potencializa o abandono das atividades do campo pelas mulheres, as quais ainda jovens saem das zonas rurais em busca de emprego e progressão nos estudos. Amorim, Fiúza \& Pinto (2015) apontam que a transformação da produção de cunho familiar em produção assalariada pode minimizar a precarização do trabalho agrícola feminino.

A valorização do produto confeccionado impulsiona a produção: Agricultora 6 "Gosto de fazer artesanato, porque vendo e as pessoas gostam...". Nesta fala, o critério reconhecimento é ressaltado e diretamente relacionado à autoestima. Isso impulsiona a produção, à medida que as pessoas demostram o apreço pelo produto oriundo das mãos dessa mulher, 
contribuindo com a elevação da autoestima dela e estimulando a produção. As atividades também estão atreladas ao bem estar: Agricultora 9 "Cuidar das plantas, porque me sinto bem fazendo isso e também fazendo artesanato".

Outras dizem que: Agricultora 12 "Gostaria de aprender mais a cozinhar coisas diferentes aprender a costurar"; Agricultora 6 "Queria fazer bolo". No apontamento desta última, pode ser levantada a seguinte reflexão: mesmo tendo um grupo de mulheres (6) trabalhando de forma organizada na produção de bolos, por qual motivo ainda tem mulheres da região que desejam participar e não participam dessa produção? Possivelmente, o estabelecimento de uma direção e uma representação ativa poderia proporcionar a essas mulheres mais coesão, autonomia e aumento da diversificação, produção e oferta de produtos a serem comercializados.

Na visão do economista Amartya Sen (2010), o indivíduo pode escolher o tipo de vida que ele quer ter. É uma visão mais ampla de desenvolvimento, que abre espaço para a participação e valorização do indivíduo nas diversas áreas, onde a ausência de escolha pode ser entendida como ausência de liberdade (Sen, 2010). Assim, as mulheres podem e têm o direito de escolher as atividades que desejam desenvolver, seja no campo, na cidade ou mesmo permanecer no lar. Suas escolhas não necessariamente poderão ser as mesmas, já que as sociedades se organizam sob bases religiosas, econômicas, políticas e ambientais diferentes.

Diante de pesquisas que vêm sendo desenvolvidas no semiárido brasileiro, sobre a retomada do cultivo de oleaginosas, foi indagado o posicionamento das mulheres agricultoras da localidade do Sitio Córrego sobre esse assunto. Foi visível que nenhuma delas tinha cultivado oleaginosas e basicamente não as conheciam, mesmo diante do fato de que alguns agricultores da região tinham participado do programa de estímulo à produção de girassol.

Observa-se então a fragilidade da coesão do grupo de agricultores, prejudicando o compartilhamento de informações, as quais seriam essenciais para ampliação do conhecimento sobre culturas alternativas a serem implantadas nas lavouras e no roçado. No entanto, quando se trata de novas culturas a serem inseridas na produção agrícola familiar, incluindo oleaginosas, as mulheres se mostraram abertas ao novo. Sessenta por cento delas demonstraram que mesmo nunca tendo cultivado oleaginosas, desejavam conhecer outras plantas e como cultivá-las.

Há o destaque de alguns pré-requisitos necessários para cultivar uma nova cultura, como seu conhecimento e seu desenvolvimento: Agricultora 4 "Conhecer a planta, como cuidar e cultivar". Foram feitas as seguintes ressalvas: a) sobre a necessidade de possuir valor agregado para produção de coprodutos: Agricultora 10 "Que tivesse valor como medicinal, óleo etc."; e b) sobre questões de planejamento: Agricultora 11 "Como cuidar, como trazer, precisa saber a quem vender, se tenho trabalho e se tenho resultado". Esses pré-requisitos destacados estão diretamente relacionados à geração de renda local: Agricultora 15 "que tenha várias utilidades, que seja útil e gere renda". Mediante essas reflexões, é possível perceber que as mulheres têm clareza do que é necessário em todas as esferas de planejamento no setor agrícola, da implantação do cultivo à comercialização do produto final.

Essas necessidades apontadas por agricultoras do Sítio Córrego foram observadas por Moura (2018, p. 251). A autora concluiu que seria necessário o desenvolvimento de oficinas de capacitação para desenvolvimento e efetivação da economia solidária, nas regiões onde as mulheres desenvolviam atividades relacionadas ao artesanato e à agricultura. Ainda destaca a necessidade de cursos que abarquem técnicas diversificadas de cultivos, para culturas diversificadas, com finalidade de melhoria da produção. Assim, as agricultoras terão mais segurança, desde o momento de preparo da terra até a colheita e a comercialização de produtos, já que a capacitação nessas áreas propiciaria maior autonomia.

A relação do grau de capacitação para a atuação no universo do empreendedorismo que se relaciona diretamente com a autonomia merece reflexão: "Acredita-se que a falta de um maior nível de escolaridade dificulta a abertura de um novo negócio pela carência de conhecimento e a maior instrução propicia a entrada no ambiente acadêmico e o não estabelecimento 
do próprio negócio" (Gonçalves et al., 2018, p.271). Salienta-se, assim, a necessidade de capacitação como fator auxiliador, de forma direta, na autonomia feminina, no contexto geral e de campesinato.

O domínio das práticas agrícolas por mulheres se configura no triunfo mais expressivo, pois elas, além de darem à luz, sabem como propiciar alimentação para sua prole (Paulilo, 2016), exercendo um papel essencial na sobrevivência da família. No espaço amostral aqui estudado não é perceptível a mulher como chefe de família, ou seja, a principal responsável pela renda familiar, uma vez que apenas 13\% são de mulheres solteira e separada. Sobre esse aspecto Leandro e Morais (2017) destacam:

A estrutura determinada, ou seja, o pai a mãe e a prole é rompida devido alguns fatores como o divórcio, viuvez ou o fato se serem mães solteiras. Assim, o genitor deixa de ser o sustentáculo econômico principal e mãe assume a obrigação, muitas vezes sem auxílio do ex-companheiro (como o pagamento de pensão alimentícia), onde essa tem a incumbência de cuidar dos filhos e do lar." (Leandro e Morais, 2017p. 19).

Estas mulheres desenvolvem diversas tarefas como o cuidado com o lar, com o cônjuge e com a maternidade causando uma sobrecarga no âmbito psicológica e física. Na agricultura, cuidam dos animais, do plantio, da colheita, da preparação de mercadorias para a comercialização e da efetivação da comercialização, como relatado no presente estudo, corroborando o observado por Mesquita:

São mulheres polivalentes, dispostas a executar qualquer trabalho que o campo exija, são estas que selecionam as melhores sementes para o plantio na horta, e ainda, por cultivar espécies originais de plantas e sementes... Essas mulheres são responsáveis por ajudar na oferta de produtos orgânicos vendidos nas feiras locais por preços bem mais acessíveis do que os oferecidos nos grandes supermercados" (Mesquita, 2018).

As múltiplas tarefas, todas equilibradas para proporcionar melhores condições de vida/sobrevivência da família. Muitas vezes estas múltiplas tarefas causam adoecimento físico e psicológico devido a sobrecarga de atividades e responsabilidades, no entanto, ainda assim, essas mulheres são subestimadas e subvalorizadas.

\section{Considerações Finais}

As mulheres agricultoras do Sítio Córrego têm participação ativa e efetiva em atividades agrícolas familiares que abarcam do cultivo à comercialização do excedente da colheita. Desenvolvem atividades múltiplas para garantir a complementação do sustento do lar e, muitas vezes, ocorre à extrapolação das suas atividades nos setores doméstico, agrícola e comercial.

As agricultoras do sítio córrego são mulheres com muitas habilidades, atividades e anseios. Anseios estes que estão voltados à segurança financeira da família. São dispostas a aprender a cultivar outras culturas que tenham elevado potencial econômico. Mostraram-se ainda abertas ao cultivo de oleaginosas, com visão ampliada da cadeia produtiva, enfatizando a importância de coprodutos diversificados, agregando valor às culturas e a margem de lucro, também a importância e necessidade de capacitação. Assim, a valorização das atividades desenvolvidas pelas mulheres da agricultura familiar será agente de mudanças em relação à visão do seu papel social, contribuindo para a construção de uma sociedade mais forte e saudável.

\section{Agradecimentos}

Este estudo foi parcialmente financiado pela Coordenação de Aperfeiçoamento de Pessoal de Nível Superior - Brasil (CAPES) (Código Financeiro 001) e Ministério da Ciência, Tecnologia e Inovação - Brasil (MCTI). 


\section{Referências}

Alves, G. S., Sell, L. B. \& Castro, A. M. (2018) trabalho da mulher no campo e suas invisibilidades. Revista Sures, n. 11.

Arzabe, C. \& Martins, A. L. S. (2018) Situação da mulher no Brasil, assimetrias e esforços na Embrapa e na agricultura. Embrapa Solos-Capítulo em livro técnico (INFOTECA-E).

Azevedo, M. B. A.\& Nunes, E. M.(2013) As feiras da agricultura familiar: um estudo na rede Xique Xique nos territórios Açu-Mossoró e Sertão do Apodi (RN). Revista GeoTemas, 3(2), 59-74.

Brandão, A. A. P. \& Santos, N. C. (2016) Capital Social e Dilemas da Ação Coletiva: Avaliando os Resultados de um Centro Comunitário de Produção voltado para Agricultores Familiares Assentados no Mato Grosso do Sul. Mediaçðes, 21(1), 384.

Brasileiro, R. S. (2009) Alternativas de desenvolvimento sustentável no semiárido nordestino: da degradação à conservação. Scientia Plena, 5(5).

Chayanov, A. V. (1974) La organización de la unidad económica campesina. Ediciones Nueva Visión, Buenos Aires, p. 342.

Cunha, L. H. (2003) Saberes Patrimoniais Pesqueiros. Desenvolvimento e Meio Ambiente, n. 7, p. 69-76.

Aquino, J. R., Freire, J. A, \& Carvalho, A. C. AT. (2018) importância, heterogeneidade e pobreza da agricultura familiar no estado do rio grande do norte. Revista Geotemas, 7(2), 66-92.

Amorim, É. O., Fiúza, A. L. D. C., \& Pinto, N. M. D. A. (2015) mulher e trabalho no meio rural: como alcançar o empoderamento?. Caderno Espaço Feminino, Seção. Dossiê 28(1), 2015.

Fao, (2013) Aumenta el porcentaje de mujeres a cargo de explotaciones agropecuarias en América Latina y el Caribe. http://www.fao.org/3/as107s/as107s.pdf.

Fao (2015) Nota técnica Gender and Land Statistics Recent developments in FAO's Gender and Land Rights Database. Disponível em: http://www.fao.org/3/a-i4862e.pdf.

Ferreira, G. B., da Costa, M. B. B., da Silva, M. S. L., Moreira, M. M., Gava, C. A., Chaves, V. C. \& Mendonça, C. E. (2011) Sustentabilidade de agroecossistemas com barragens subterrâneas no semiárido brasileiro: a percepção dos agricultores na Paraíba. Revista Brasileira de Agroecologia, 6(1), 1936 .

Giulietti, A. M., Bocage Neta, A. L. D., Castro, A. A J. F., Gamarra-Rojas, C. F. L., Sampaio, E. V. S. B., Virgínio, J. F., Queiroz, L. P., Figueiredo, M. A., Rodal, M. J. N, Barbosa, M. R, V. \& Harley, R. M.(2004) Diagnóstico da vegetação nativa do bioma Caatinga. Biodiversidade da Caatinga: áreas e ações prioritárias para a conservação.

Gonçalves, L. A., Queiroz, J. V., Krüger, G. N. \& Brito, R. T. (2018) análise do perfil das mulheres empreendedoras do RN, IN: BRASIL, D. F. et al. Autonomia econômica das mulheres: dados, contribuições e estratégias para a inserção e permanência das mulheres do Rio Grande do Norte no mundo do trabalho. Gráfica e editora Caule de paraíso, p. 255-274.

Heredia, B. M. A. (2013) A morada da vida: trabalho familiar de pequenos produtores do Nordeste do Brasil. Rio de Janeiro, Centro Edilston de pesquisas sociais, Edição Online, p. 127.IBGE, Cesno agropecuário 2017. https://biblioteca.ibge.gov.br/visualizacao/periodicos/3093/agro_ 2017_resultados_preliminares.pdf.

Leonardo, F. A. M. \& Morais, A. G. L. (2017) Família monoparental feminina: a mulher como chefe de família. Revista do Instituto de Políticas Públicas de Marília, 3(1), 11-22.

Lopes, M. J. M. \& Langbecker, T. B. (2018) Inclusão produtiva, pecuária familiar e situação das mulheres rurais do Programa Brasil Sem Miséria em um município do RS-contexto de uma realidade pouco conhecida. REDES: Revista do Desenvolvimento Regional, 23(1), 31-52.

Macedo, M. G. M., Oliveira, A. F., Araújo, T. U., Gonçalves, L. A., Gisely Lacerda Gomes, G. L \&. Isolda Muniz Batista, I. M.. (2018) Inserção da mulher no mercado trabalho, IN: BRASIL, D. F. et al. Autonomia econômica das mulheres: dados, contribuições e estratégias para a inserção e permanência das mulheres do Rio Grande do Norte no mundo do trabalho. Gráfica e editora Caule de paraíso, p. 13-61.

Mahl, Á. C., Stein, J. \& Costa, A. B. (2017) Ocorrência de transtornos mentais em mulheres agricultoras familiares e estratégias de cuidado ofertadas no município de Saudades-SC. VITTALLE-Revista de Ciências da Saúde, 29(2), 23-34.

Maia, Z. M. G. \& Siqueira, E. S. (2011) O papel das mulheres na reconstrução do conceito de ruralidade: uma experiência de trabalho feminino da Associação de Mulheres Pescadoras e Artesãs do Município de Grossos-RN. Cadernos de Agroecologia, 6(2).

Mapa, (2018) Ministério da Agricultura e Abastecimento, Secretaria de Agricultura Familiar e cooperativismo, Sead apresenta o Selo Mulheres Rurais e Campanha Mulheres Rurais Mulheres com Direitos no $5^{\mathrm{a}}$ CNSAN+2. 2018. http://www.mda.gov.br/sitemda/noticias/sead-apresenta-o-selo-mulheres-rurais-ecampanha-mulheres-rurais-mulheres-com-direitos-no

Mapa, Ministério da Agricultura, Pecuária e Abastecimento, Mulheres rurais se destacam em diferentes atividades e buscam acesso a direitos, 2019. http://www.agricultura.gov.br/noticias/mulheres-rurais-se-destacam-em-diferentes-atividades-e-buscam-visibilidade-para-seus-direitos.

Medeiros, R. M. \& Ribeiro, E. M.(2003) O papel da mulher na agricultura familiar: dois estudos de caso. Organizações Rurais \& Agroindustriais, 5(1). Meira, A. L., Santos, P. R. P., Conceição Júnior, V., Oliveira, D. F. D., Oliveira, H. H. \& Souza, S. E. D. (2013). Uma abordagem sobre o papel da mulher na cadeia produtiva do café no município da Barra do Choça-Bahia. 2013.

Meksenas, P. (2002) Pesquisa social e ação pedagógica conceitos, métodos e ráticas, edições Loyola, São Paulo, Brasil. 
Mesquita, R. N. (2018) Diálogos femininos-trajetórias plurais: um estudo de caso dos projetos de assentamento rurais espinhara e polo Antônio de Holanda no município de Bujari, Acre. Revista Presença Geográfica, 4(2), 70-76.

Miller, F. S. (2012) Pescadores e coletoras de Patané/Camocim: aspectos da adaptação humana aos manguezais do Rio Grande do Norte. Natal, RN: EDUFRN.

Moura, T. F. (2018) autonomia econômica e mercado de trabalho: uma análise do perfil de mulheres do Rio Grande do Norte, IN: BRASIL, D. F. et al. Autonomia econômica das mulheres: dados, contribuições e estratégias para a inserção e permanência das mulheres do Rio Grande do Norte no mundo do trabalho. Gráfica e editora Caule de paraíso.

Nascimento, A. C., Rocha, R. G. \& Mendonça, M. R. (2018) Movimentos contra-hegemônicos: o papel da mulher na agricultura campesina. InterEspaço: Revista de Geografia e Interdisciplinaridade, 3(10), 214-233.

Neves, D. \& Medeiros, L. (2013) Mulheres camponesas: trabalho produtivo e engajamentos políticos. Niterói: Alternativa.

Paulilo, M. I. S. (2017) Movimentos de mulheres agricultoras e ecologia in: Delgado, G. C.; Bergamasco, S. M. P. P. Agricultura familiar brasileira: desafios e perspectivas de futuro. Brasília: Ministério do Desenvolvimento Agrário.

Paulilo, M. I. S.(2000) Mulher e cidadania. Serviço Social em Revista, p. 227-44.

Paulilo, M. I. S. (2016) Que feminismo é esse que nasce na horta?. Política \& Sociedade, v. 15, p. 296-316.

Pnad, Pesquisa Nacional por Amostra de Domicílio 2015. https://biblioteca.ibge.gov.br/visualizacao/livros/liv98887.pdf

Quaresma, A. P. (2015) Mulheres e quintais agroflorestais: a “ajuda invisível” aos olhos que garante a reprodução da agricultura familiar camponesa amazônica. Coletânea Sobre Estudos Rurais E Gênero, p. 35.

Rebouças, M. A. \&Lima, V. L. A. (2013) Caracterização socioeconômica dos agricultores familiares produtores e não produtores de mamão irrigado na agrovila canudos, Ceará mirim (RN). HOLOS, v. 2, p. 79-95.

Sachs, I. (2008) Desenvolvimento : ineludente, sustentável, sustentado . Rio de Janeiro : Garamond, p. 152.

Scott, P. R. (2009) Famílias camponesas, migrações e contextos de poder no Nordeste: entre o "cativeiro" e o " meio do mundo". In: Diversidade do campesinato: expressões e categorias:construções identitárias e sociabilidades, Emília P. G.; MArílda, A. M., Rosa, A. M. (Orgs)-São Paulo: Editora UNESP; Brasília, DF, Núcleo de Estudos Agrários e Desenvolvimento Rural, 70, 245.

Sen, A. (2010) Desenvolvimento como liberdade. Companhia de Bolso, p. 464.

Silva, C.C. \& Schneider, S. (2010) Gênero, Trabalho Rural e Pluralidade. IN: Scott, P., Cordeiro, R.\& Menezes, M., (org.) Gênero e Geração em Contexto Rurais. Florianópolis: Mulheres, p. 183-207.

Silva, M. R.(2019) Gênero, desigualdades e agricultura: a mulher na atividade agrícola familiar/Gender and inequalities: reflections on women in family agricultural activity. Brazilian Journal of Development, 5(3), 2095-2105.

Strate, M. F. D. 1. \& Conterato, M. A.(2019) Práticas de agroindustrialização e arranjos produtivos locais como estratégia de diversificar e fortalecer a agricultura familiar no Rio Grande do Sul. Redes (Santa Cruz do Sul. Online), 24(1), 227-245.

Saffioti, H. I. B. (1991) Novas perspectivas metodológicas de investigação das relações de gênero. In Moraes Silva, M.A. Mulher em seis tempos. Araraquara: FCL-UNESP.

Varotto, D. P. (2017) Agroecologia e gênero: perspectivas para a emancipação das mulheres e a agricultura familiar. RELACult-Revista Latino-Americana de Estudos em Cultura e Sociedade, 3(3).

Vespucci, I. L., Nunes, M. P. C., Guimarães, H., \& Silva, D. D. A. (2019). Agricultura familiar: a realidade das famílias pertencentes ao município de Moiporá-GO. REINPG (Online), 2(1), 13-21.

Wanderley, M. N. B. (2014). O campesinato brasileiro: uma história de resistência. Revista de economia e sociologia rural, 52, $25-44$.

Woortmann , E. F. (2009) O saber camponês: práticas ecológicas tradicionais e inovações. In: Diversidade do campesinato: expressões e categorias:construções identitárias e sociabilidades, Emília, P. G.; Marílda, A. M.; Rosa A. M.(Orgs)-São Paulo:Editora UNESP; Brasília, DF, Núcleo de Estudos Agrários e Desenvolvimento Rural, v.2.

Zanchi, V. \& Souza, M. B.(2019) Agricultura familiar no Vale do Rio Pardo (RS): reflexões sobre o saber-fazer das mulheres. COLÓQUIO, 16(1), 83-98, 2019. 